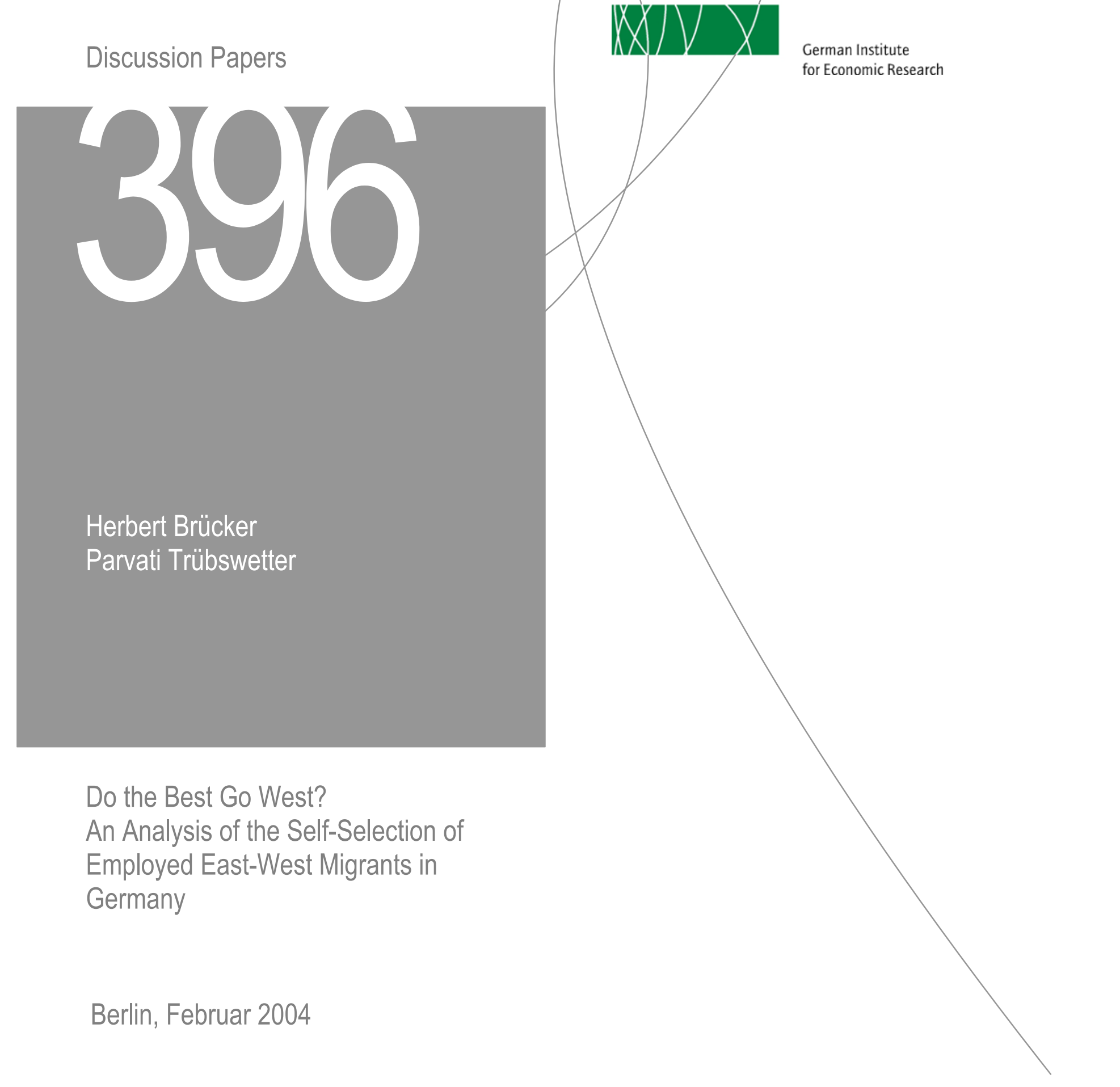


Opinions expressed in this paper are those of the author and do not necessarily reflect views of the Institute.

DIW Berlin

German Institute

for Economic Research

Königin-Luise-Str. 5

14195 Berlin,

Germany

Phone +49-30-897 89-0

Fax $\quad+49-30-89789-200$

www.diw.de

ISSN 1619-4535 


\title{
Do the Best Go West? An Analysis of the Self-Selection of Employed East-West Migrants in Germany*
}

\author{
Herbert Brücker and Parvati Trübswetter**
}

December 17, 2003

\begin{abstract}
Since the inequality of earnings in East Germany has approached West German levels in the late 1990s, the standard Roy model predicts that a positive selection bias of East-West migrants should disappear. Using a switching regression model and data from the IABemployment sample, we find however that employed East-West migrants remain positively self-selected with respect to unobserved abilities. This result is consistent with the predictions of our extended Roy model which considers moving costs that are negatively correlated with labour market abilities of individuals. Moreover, we find that wage differentials as well as differences in employment opportunities are the central forces which drive East-West migration after unification.
\end{abstract}

Key Words: Migration, self-selection, East Germany.

JEL: R23, J61, P23

${ }^{*}$ Financial support from the $5^{\text {th }}$ Framework Programme of the European Commission, project "Regional Labour Market Adjustment in the Accession Candidate Countries", is gratefully acknowledged. Data used in the paper are available from the Zentralarchiv für Empirische Sozialforschung, Universität zu Köln.

ॠGerman Institute for Economic Research (DIW Berlin) and Institute for the Study of Labor (IZA), Bonn. DIW Berlin, Königin-Luise-Straße 5, D-14195 Berlin, Germany, E-mail: hbruecker@diw.de, Tel. +49-30-8 97 89-442, Fax +49-30-8 97 89-108.

${ }^{* *}$ Ludwig-Maximilians University Munich, Department of Economics 


\section{Introduction}

Cumulative net migration from East to West Germany amounts to 1.3 million persons or 7.5 per cent of the original population in East Germany over the period from 1989 until the end of 2001. With that number, East Germany shows together with Albania the highest emigration rate among the countries formerly behind the iron curtain. Although net emigration rates in East Germany declined sharply after the currency union was announced, East-West migration has tended to increase again since 1996. The persistent phenomenon of East-West migration has raised increasing concerns that individuals with high abilities and qualifications migrate to the West and that this "brain drain" will contribute further to sluggish economic growth and diverging per capita income levels.

Indeed, for an understanding of the economic consequences of migration an analysis of the forces which drive the composition of the migrant population is crucial. The impact of migration on wages and employment opportunities of natives as well as the labour market performance and welfare dependency of the migrants themselves is determined by the structure of the migrant population with respect to their abilities and human capital characteristics. Thus, the self-selection of migrants has important consequences for economic growth, labour markets and the fiscal balance of the welfare state.

The self-selection of migrants has attracted increasing attention in the migration literature since the seminal paper of Borjas (1987), who applied the Roy (1951) model to the migration decision. In the Roy model, the selfselection of individuals depends essentially on the relative returns to their abilities, such that the distribution of income in the home and the host region determines the composition of migrants. As a result, migrants were positively selected at the inequality in the distribution of income is higher in the host region than in the home region - and vice versa (Borjas, 1987, pp. 551-52). Thus, the standard Roy model predicts that migrants from the East were positively selected at the beginning of the transition process, since the distribution of earnings was more equal in East Germany than in West Germany in the early 1990s. However, this positive selection bias should 


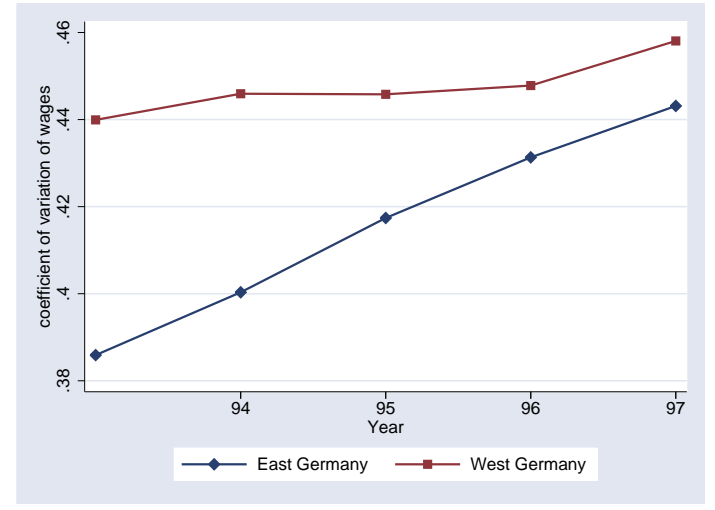

Figure 1: Wage Inequality in East and West Germany

have disappeared over time, as the inequality of earnings in East Germany has meanwhile almost approached West German levels (see Figure 1).

The strong results from the standard Roy model are, however, controversial, especially because the empirical evidence provided for its predictions is not conclusive. Borjas (1987) analyses the the development of earnings of migrants in the host region, which allows no direct inference on the question of whether migrants are drawn from the upper or the lower tail of the income distribution in their home countries. Moreover, Borjas' (1987) conclusion that the "quality" of US migrants has declined over time has been questioned (Jasso and Rosenzweig, 1990). Thus, many authors argue that migrants are presumably favourably selected although the variance of earnings is higher in the home region relative to the host region.

An empirical analysis of selection bias in the context of international migration is seriously hampered by a lack of individual data. Household panels in the home countries usually do not allow international emigrants to be identified - they simply disappear from the panel. Thus, although we have rich information on immigrants in many host countries, the phenomenon of self-selection cannot be addressed systematically on the basis of standard data sources.

German unification offers a unique opportunity to study the problem of the selection of migrants. There exist several micro data sets that allow EastWest migrants to be identified before and after movement. We employ the 
"IAB-Regionalstichprobe", which is a one per cent sample of individuals who are registered by the German social security system and includes individuals in both parts of Germany. This data set enables us to analyse whether and to what extent relative returns to abilities affect the self-sorting of EastWest migrants. The empirical framework is based on a switching regression model (Goldfeld and Quandt, 1973) with endogenous switching (Maddala and Nelson, 1975; Maddala, 1983). The switching regression model can be derived from the Roy model and was first applied in the context of migration decisions by Nakosteen and Zimmer (1984). It makes it possible not only to estimate the wage differential for (prospective) migrants consistently, but also enables us to draw inferences on the selection bias of the migrant population.

The remainder of the paper is structured as follows: firstly, we briefly review the findings of the empirical literature on East-West migration in Germany (Section 2). Secondly, we present an extended version of Roy's model which considers the correlation between moving costs and abilities of individuals in the labour market. As a result, the strong predictions of Roy's model are relaxed or even reversed (Section 3). Thirdly, we describe the data base (Section 4) and analyse the socio-economic characteristics of migrants (Section 5). Fourthly, we present the switching regression model and discuss the econometric results (Section 6). In conclusion we summarise our findings and their implications for the theory and empiry of self-selection (Section 7).

\section{Empirical literature}

There exists a large body of literature on East-West migration in Germany that addresses the problem of self-selection at least partially. At first glance, this literature seems to confirm the hypothesis that "those who emigrate tend to be better educated and possibly better workers in unobservable ways than stayers" (Burda and Hunt, 2001, p. 65). In her comprehensive analysis of German East-West migration, Hunt (2000) finds, based on individual data from the German Socio-Economic Panel (GSOEP), that migrants are disproportionately high skilled if controlling for age and gender. However, they are disproportionately low skilled if those control variables are not in- 
cluded. Hunt interprets this as evidence that, in particular, the young and high-skilled tend to move. Based on an analysis of migration intentions as revealed in the GSOEP, Burda (1993) shows that those having completed secondary schooling with an Abitur (academic secondary schooling exam) intend to move over proportionally, while those with a university or other tertiary education degree intend to move less frequently than other education groups (Burda, 1993, p. 460). Similar results can be found in Burda, Härdle, Müller, and Werwatz (1998). In contrast, the results of Schwarze (1996) indicate that years of education are positively correlated with migration intentions as well as with actual migration. Analogously, Pischke, Staat, and Vögele (1994) show on basis of data from the "Arbeitsmarktmonitor" that East-West commuters possess higher skill levels than stayers.

Moreover, the results in the empirical literature regarding the impact of the wage differential on the propensity to migrate are ambiguous. While Schwarze (1996) finds that the wage differential affects individual migration probabilities positively, the results of Hunt (2000) and Burda, Härdle, Müller, and Werwatz (1998) indicate that no unambiguous correlation between the wage differential and the propensity to migrate exists. Burda, Härdle, Müller, and Werwatz (1998) interpret the non-linear relation between the income differential and migration probabilities in their estimates as evidence for the option value of waiting theory of migration. However, to the best of our knowledge, no paper on the determinants of East-West migration considers the self-selection of migrants. Thus, the results might be affected by selection bias.

Altogether, the results of the empirical literature regarding the question whether migrants from East Germany are positively selected are not conclusive. Furthermore, the empirical literature on the determinants of East-West migration does not consider the selection of migrants with regard to unobservable abilities in the labour market, which may bias their results. 


\section{Theoretical framework}

The self-selection of migrants is affected by various factors since both the benefits as well as the costs of migration are not equally distributed across the population. The Roy model offers a rigorous and theoretically powerful framework to analyse the self-selection of individuals. According to the Roy model, self-selection is driven by comparative advantage of individuals. As a consequence, the distribution of income in the host and the home region determines whether individuals with higher or lower abilities tend to migrate: if the distribution of income in the host region is more equal than in the home region, and if the correlation between the incomes of (potential) migrants in both locations is positive, migrants are chosen from the lower tail of the income distribution and vice versa (Borjas, 1987, pp. 551-52).

In its original formulation, the Roy model does not consider any switching costs. In the context of migration, pecuniary and non-pecuniary moving costs are, however, an important factor which cannot be ignored in the analysis of the migration decision. Moreover, it is reasonable to assume that abilities relevant for the labour market performance of individuals and moving costs are negatively correlated, i.e. that the same human capital characteristics which yield higher returns in the labour market allow individuals to better reduce moving costs. In this more general framework, migrants may be chosen from the upper tail of the income distribution although the distribution of income in the host region is more equal than in the home region. ${ }^{1}$

In what follows, we discuss first the mechanics of an extended Roy model which considers the correlation between labour market abilities and moving costs in order to derive the framework for the empirical analysis and then present the estimation model.

\footnotetext{
${ }^{1} \mathrm{~A}$ similar point has recently been made by Chiswick (2000): He demonstrates in a numerical example that the strong implications of the Roy model are relaxed if fixed moving costs are considered.
} 


\subsection{An extension of the Roy model}

Suppose that $w_{1}$ is the wage of residents in the home region (region 1 ), and $w_{2}$ the wage of residents in the host region (region 2). Assume that log wages in region 1 and region 2 have a joint normal distribution, such that

$$
\ln w_{1}=\mu_{1}+\varepsilon_{1},
$$

where $\mu_{1}$ is the mean of the log wage in region 1 and $\varepsilon_{1}$ a normally distributed disturbance with zero mean and variance $\sigma_{1}^{2}$. Analogously,

$$
\ln w_{2}=\mu_{2}+\varepsilon_{2}
$$

where $\varepsilon_{2}$ is normally distributed with zero mean and variance $\sigma_{2}^{2}$. The Roy model focuses on the impact of selection bias on the disturbances $\varepsilon_{1}$ and $\varepsilon_{2}$, which can be interpreted as (unobservable) abilities of individuals.

The original Roy model ignores all switching costs, i.e. an individual from region 1 migrates into region 2 if $w_{2}>w_{1}$. However, it is reasonable to assume that moving costs exist and that they are related to human capital characteristics and other abilities of individuals. Suppose that $C$ represents the pecuniary and non-pecuniary costs of migration as a proportion of home income. Migration occurs if $\frac{w_{2}-w_{1}}{w_{1}}>C$, or, approximately, if $\ln w_{2}-\ln w_{1}>$ $C$. Assume that $C$ is normally distributed with mean $\tau$ and disturbance $\eta$, i.e.

$$
C=\tau+\eta,
$$

and that $\eta \sim N\left(0, \sigma_{\eta}^{2}\right)$. The decision to migrate is then determined by the sign of the index function, $I^{*}$, which contains the wage gain from moving minus the costs of migration:

$$
I^{*}=\mu_{2}-\mu_{1}-\tau+\varepsilon_{2}-\varepsilon_{1}-\eta
$$

i.e. an individual migrates if $I^{*}>0$, and stays at home if $I^{*} \leq 0$. 
Define

$\sigma^{*}=\sqrt{\operatorname{Var}\left(\varepsilon_{2}-\varepsilon_{1}-\eta\right)}, \quad z=-\frac{\mu_{2}-\mu_{1}-\tau}{\sigma^{*}}, \quad$ and $\quad \epsilon=\frac{\varepsilon_{2}-\varepsilon_{1}-\eta}{\sigma^{*}}$.

Migration occurs if $\epsilon>z$. Under the normality assumptions, the migration rate $m$ is given by

$$
m=\operatorname{Pr}(\epsilon>z)=1-\Phi(z)
$$

where $\Phi()$ is the cumulative distribution function of the standard normal. Using the standard sample selection formula (Heckman, 1976, 1979), the (unobserved) wage of a migrant in the home region can be written as

$$
E\left(\ln w_{1} \mid I^{*}>0\right)=\mu_{1}+\sigma_{1 \epsilon} \lambda(z)
$$

and the observed wage in the host region as

$$
E\left(\ln w_{2} \mid I^{*}>0\right)=\mu_{2}+\sigma_{2 \epsilon} \lambda(z)
$$

where $\sigma_{1 \epsilon}$ and $\sigma_{2 \epsilon}$ are the covariance of $\varepsilon_{1}$ and $\epsilon$, and the covariance of $\varepsilon_{2}$ and $\epsilon$, respectively, and

$$
\lambda(z)=\frac{\phi(z)}{1-\Phi(z)}
$$

is the inverse of Mills' ratio and $\phi()$ the density of the standard normal.

Whether migrants are better or worse off than the average person in the home and the host region depends on the sign of the second term in the equations (6) and (7). Since $\lambda(z) \geq 0$ by definition, the average migrant is better off than the average person in the home region if $\sigma_{1 \epsilon}>0$, and, analogously, better off than the average person in the host region if $\sigma_{2 \epsilon}>0$ - if we ignore the limiting case that $\lambda(z)=0$.

An interpretation of these conditions requires that we decompose $\sigma_{1 \epsilon}$ and $\sigma_{2 \epsilon}$. Using the definition for the covariance, we can rewrite $\sigma_{1 \epsilon}$ as

$$
\sigma_{1 \epsilon}=\frac{\sigma_{12}-\sigma_{1}^{2}-\sigma_{1 \eta}}{\sigma^{*}}
$$


and $\sigma_{2 \epsilon}$ as

$$
\sigma_{2 \epsilon}=\frac{\sigma_{2}^{2}-\sigma_{12}-\sigma_{2 \eta}}{\sigma^{*}}
$$

Thus, we can derive two fundamental conditions for the favourable selfselection of migrants: firstly, migrants are better off than the average person in the home population if $\sigma_{12}>\sigma_{1}^{2}+\sigma_{1 \eta}$, or if

$$
\frac{\sigma_{2}}{\sigma_{1}}>\frac{1}{\rho_{12}}+\frac{\rho_{1 \eta}}{\rho_{12}} \frac{\sigma_{\eta}}{\sigma_{1}}
$$

where $\rho_{12}$ is the correlation coefficient between $\varepsilon_{1}$ and $\varepsilon_{2}$, and $\rho_{1 \eta}$ the correlation coefficient between $\varepsilon_{1}$ and $\eta$. We assume for the further analysis that $\rho_{12}>0$, since a negative correlation between earnings in both regions makes no sense economically. Note that the second term on the right-hand side captures the correlation between labour-market abilities and moving costs. Since we assume that labour-market abilities and moving costs are negatively correlated, i.e. that $\rho_{1 \eta}<0$, the second term is negative, and, hence, increases the probability of a favourable selection of migrants relative to the average person in the home population for a given variance of earnings in the host and the home region.

Secondly, the migrant is better off than the average person in the host region if $\sigma_{2}^{2}>\sigma_{12}+\sigma_{2 \eta}$, or if

$$
\frac{\sigma_{2}}{\sigma_{1}}>\rho_{12}+\rho_{2 \eta} \frac{\sigma_{\eta}}{\sigma_{1}}
$$

where $\rho_{2 \eta}$ is the correlation coefficient between $\varepsilon_{2}$ and $\eta$. Once again, since we assume that $\rho_{2 \eta}<0$, the second term on the right-hand side increases the probability of a favourable selection of migrants relative to the average person in the host population for a given variance of earnings in the host and the home region.

\subsection{Comparative Statics}

Consider now the implications of the model for a change in the economic conditions underlying the (self-)selection of migrants. We can write the selection 
bias of migrants relative to the average person in the home population as

$$
S_{j}=S_{j}\left(\omega, C, \sigma_{1}, \sigma_{2}, \eta, \rho_{12}, \rho_{1 \eta}, \rho_{2 \eta}\right), \quad j \in\{1,2\}
$$

where $\omega \equiv \mu_{2}-\mu_{1}$ is the income difference between the host and the home region. The second terms in equations (6) and (7) show that the selection bias in the home region is given by

$$
S_{1}=\sigma_{1 \epsilon} \lambda(z)
$$

and in the host region by

$$
S_{2}=\sigma_{2 \epsilon} \lambda(z) .
$$

We can thus write the impact of a change in any variable $x$ on the change in $S_{1}$ and $S_{2}$ as

$$
\frac{\partial S_{1}}{\partial x}=\frac{\partial \sigma_{1 \epsilon}}{\partial x} \lambda+\frac{\partial \lambda}{\partial x} \sigma_{1 \epsilon}
$$

and as

$$
\frac{\partial S_{2}}{\partial x}=\frac{\partial \sigma_{2 \epsilon}}{\partial x} \lambda+\frac{\partial \lambda}{\partial x} \sigma_{2 \epsilon} .
$$

The first term on the right-hand side in equations (10) and (11) captures the composition effect for a constant scale of migration, and the second term the scale effect for a given composition of the migrant population (Borjas, 1987).

We focus here on the selection bias of migrants relative to the average person in the home region. Define $k=\sigma_{2} \rho_{12}-\sigma_{1}-\sigma_{\eta} \rho_{1 \eta} . k$ has a positive sign if $\frac{\sigma_{2}}{\sigma_{1}}>\frac{1}{\rho_{12}}+\frac{\rho_{1 \eta}}{\rho_{12}} \frac{\sigma_{\eta}}{\sigma_{1}}$, i.e. if migrants are positively selected, and a negative one, if otherwise.

Consider first the impact of a change in the difference of earnings between the host and the home region. Using equation (10) it can be shown that

$$
\frac{\partial S_{1}}{\partial \omega}=-\frac{\sigma_{1}}{\sigma^{* 2}} \frac{\partial \lambda}{\partial z} k
$$

i.e. a change in the income differential affects the composition of migrants only via the scale effect. An increase in the difference of earnings between the host and the home region reduces the positive (negative) selection bias 
of the migrant population if they are positively (negatively) selected. The intuition behind this result is that a higher difference in earnings increases the share of migrants in the population, which in turn reduces the selection bias in both directions, since migrants are increasingly drawn from the mean parts of the income distribution.

Increasing the mean costs of migration has the opposite effect, i.e.

$$
\frac{\partial S_{1}}{\partial C}=\frac{\sigma_{1}}{\sigma^{* 2}} \frac{\partial \lambda}{\partial z} k
$$

since increasing moving costs reduces the share of migrants in the population, which in turn increases the selection bias of the migrant population.

The impact of a change in the inequality of earnings on the selection bias is ambiguous. The derivation of $S_{1}$ with respect to $\sigma_{1}$ yields

$$
\frac{\partial S_{1}}{\partial \sigma_{1}}=\frac{2 \sigma_{1} k^{2}-\left(\sigma_{1}-k\right) \sigma^{* 2}}{\sigma^{* 3}} \lambda+\frac{\sigma_{1} k^{2}}{\sigma^{* 3}} \frac{\partial \lambda}{\partial z} z
$$

where the sign of the first term - the composition effect - is positive if $2 \sigma_{1}\left(\sigma_{1}-\rho_{12} \sigma_{2}+\rho_{1 \eta} \sigma_{\eta}\right)^{2}>\left(2 \sigma_{1}-\rho_{12} \sigma_{2}+\rho_{1 \eta} \sigma_{\eta}\right) \sigma^{* 2}$, which depends on the value of the parameters. The impact of the second term - the scale effect - depends on the sign of $z$. If the net difference in mean earnings (incl. moving costs) is positive (i.e. $z<0$ ), the scale effect is negative, and positive if otherwise. Intuitively, with a higher inequality of earnings in the home region, the incentives to migrate for those who are better off decline, while those at the lower tail of the income distribution still want to migrate, such that the migrant population becomes increasingly negatively selected with an increasing inequality of income in the home region.

The effect of an increasing inequality of earnings in the host region is again ambiguous. Analogously to equation (14), a derivation of $S_{2}$ with respect to $\sigma_{2}$ gives

$$
\frac{\partial S_{1}}{\partial \sigma_{2}}=\frac{\sigma_{1}\left(\rho_{12} \sigma^{* 2}-k n\right)}{\sigma^{* 3}} \lambda-k n \frac{\sigma_{1}}{\sigma^{* 3}} \frac{\partial \lambda}{\partial z} z,
$$

where $n$ is defined as $\sigma_{2}+\rho_{12} \sigma_{1}-\rho_{23} \sigma_{\eta}>0$. The composition effect has a positive sign if $\rho_{12} \sigma^{* 2}>k n$, which is always the case if a negative selection 
bias of the migrant population exists. In the converse case, the sign of the composition effect depends on the sign of the individual parameters. The scale effect is positive if migrants are positively selected and the net difference in earnings between the host and the home region is positive (i.e. $z<0$ ), and negative in the converse case. Thus, an increase in the inequality of earnings in the host region strengthens a given selection bias in both directions via the scale effect if the difference in net earnings is positive, while it reduces a negative selection bias via the composition effect, and is ambiguous if a positive selection bias exists.

Finally, we can assess the implications of a change in the correlation coefficients. The derivation of the change in $S_{1}$ with respect to a change in the correlation coefficients is given by

$$
\begin{aligned}
& \frac{\partial S_{1}}{\partial \rho_{12}}=k \frac{\sigma_{1}^{2} \sigma_{2}}{\sigma^{*}} \lambda-k \frac{\sigma_{1}^{2} \sigma_{2}}{\sigma^{* 3}} \frac{\partial \lambda}{\partial z} z \\
& \frac{\partial S_{1}}{\partial \rho_{1 \eta}}=k \frac{\sigma_{1}^{2} \sigma_{\eta}}{\sigma^{*}} \lambda-k \frac{\sigma_{1}^{2} \sigma_{\eta}}{\sigma^{* 3}} \frac{\partial \lambda}{\partial z} z
\end{aligned}
$$

and

$$
\frac{\partial S_{1}}{\partial \rho_{2 \eta}}=k \frac{\sigma_{1} \sigma_{2} \sigma_{\eta}}{\sigma^{*}} \lambda-k \frac{\sigma_{1} \sigma_{2} \sigma_{\eta}}{\sigma^{* 3}} \frac{\partial \lambda}{\partial z} z .
$$

In all three equations, the composition effect and the scale effect have the same sign if the net difference in mean earnings (incl. moving costs) between the host and the home is positive $(z<0)$, and the converse sign if the net difference in mean earnings is negative $(z>0)$. Thus, an increasing (positive) correlation between earnings in the home and the host region strengthens the selection bias both via the composition effect and the scale effect if the net difference in earnings is positive. In contrast, an increasing (negative) correlation between labour market abilities and moving costs weakens the selection bias if the net difference in earnings is positive.

To sum up, the mechanics of the enhanced Roy model demonstrates that (i) a higher variance of earnings in the home region relative to the host region does not necessarily yield a negative selection bias of the migrant population, (ii) a positive selection bias is more likely to occur if we consider the cor- 
relation between labour market abilities and moving costs, (iii) increasing the difference in net earnings between the home and the host region reduces the selection bias of the migrant population, (iv) increasing the (positive) correlation between earnings in both regions strengthens the selection bias, and $(\mathrm{v})$ increasing the (negative) correlation between earnings and moving costs weakens the selection bias. Increasing the inequality of earnings in the home as well in the host region has an ambiguous effect on the selection bias. The scale effect weakens the selection bias if the inequality of home earnings increases and if the net difference in earnings is positive, and strengthens the selection bias if the inequality of host earnings increases. The sign of the composition effect depends on the value of the parameters of the model.

Thus, in the case of East-West migration in Germany, different forces may have affected the selection bias of the migrant population in different directions: first, the increasing inequality of earnings in the East may have reduced the incentives to migrate for those at the upper tail of the income distribution via the scale effect, and, hence, may have reduced the positive selection bias. Second, the convergence of wages between East and West Germany may have resulted in less migration, and, hence, increased the positive selection bias. Third, reduced moving costs may have increased migration and thus reduced the positive selection bias. Altogether, the increasing inequality of earnings in East Germany does not necessarily negatively affect the selection of migrants with regard to their abilities.

\subsection{Estimation}

The Roy model as described above can be considered a switching regression model (Goldfeld and Quandt, 1973) with endogenous switching (Maddala and Nelson, 1975; Maddala, 1983).

Rewrite the wage equations in (1) and (2) as

$$
\ln w_{1 i}=X_{1 i} \beta_{1}+\varepsilon_{1 i}
$$

and

$$
\ln w_{2 i}=X_{2 i} \beta_{2}+\varepsilon_{2 i},
$$


where $X_{i}$ is a vector of personal variables which is observed for each individual $i$. In the empirical application, we also consider regional and sectoral control variables. Suppose that the index function for the $i t h$ individual is given by

$$
I_{i}^{*}=\delta\left(\ln w_{2 i}-\ln w_{1 i}\right)-Z_{i} \gamma-\eta_{i},
$$

where $\delta$ denotes a coefficient, $Z_{i} \gamma+\eta_{i}=C_{i}$ the migration cost, and $Z_{i}$ again a vector of regional and personal variables. Note that the coefficient $\delta$ implies that migration is a log-linear function of the income difference, i.e. the functional form which we employ here for estimation differs slightly from the theoretical model. Identification of the model requires that at least one variable in $Z_{i}$ is not included in the vector $X_{i}$.

It is obvious from the discussion of the Roy model that the index function cannot be estimated in structural form since the term $\ln w_{2 i}-\ln w_{1 i}$ is endogenous. Following Lee (1978) and Willis and Rosen (1979) the model can be estimated in three steps. In the first step we estimate a reduced form of the migration function. The reduced form of the index function $I_{i}^{*}$ is given by

$$
I_{i}^{*}=\delta\left(X_{2 i} \beta_{2}-X_{1 i} \beta_{1}\right)-Z_{i} \gamma+\delta\left(\varepsilon_{2 i}-\varepsilon_{1 i}\right)-\eta_{i}=Z_{i}^{*} \gamma^{*}-\epsilon^{*}
$$

where $Z_{i}^{*}, \gamma^{*}$ and $\epsilon^{*}$ are defined suitably. Define $I_{i}=1$ if $I^{*}>0$ and $I_{i}=0$ otherwise. Based on the observations on $I_{i}$ we can then use the probit Maximum Likelihood estimator in the first step to obtain a consistent estimate for the vector $\widehat{\gamma}^{*}$.

Wages in region 1 can be observed only for those individuals for whom $I_{i}=0$, and wages in region 2 only for those individuals for whom $I_{i}=1$. Estimating the wage equations therefore requires correction for this selection bias. Using the estimated vector of parameters $\widehat{\gamma}^{*}$, we can compute the inverse Mills' ratio for migrants and stayers as $\frac{\phi\left(Z_{i}^{*} \widehat{\gamma}^{*}\right)}{1-\Phi\left(Z_{i}^{*} \widehat{\gamma}^{*}\right)}$ and $\frac{\phi\left(Z_{i}^{*} \widehat{\gamma}^{*}\right)}{\Phi\left(Z_{i}^{*} \widehat{\gamma}^{*}\right)}$, respectively. Under the normality assumptions, this allows us to correct for selection bias and to estimate in the second step the wage equations for 
stayers in the home region and movers to the host region by OLS:

$$
\ln w_{i}=X_{i} \beta_{1}-\sigma_{1 \epsilon^{*}} \frac{\phi\left(Z_{i}^{*} \widehat{\gamma}^{*}\right)}{\Phi\left(Z_{i}^{*} \widehat{\gamma}^{*}\right)}+u_{1 i}, \quad \text { for } \quad I_{i}=0
$$

and

$$
\ln w_{i}=X_{i} \beta_{2}+\sigma_{2 \epsilon^{*}} \frac{\phi\left(Z_{i}^{*} \widehat{\gamma}^{*}\right)}{1-\Phi\left(Z_{i}^{*} \widehat{\gamma}^{*}\right)}+u_{2 i}, \quad \text { for } \quad I_{i}=1,
$$

which gives us consistent estimates of $\beta_{1}, \beta_{2}, \sigma_{1 \epsilon^{*}}$, and $\sigma_{2 \epsilon^{*}}$. Furthermore, it is possible to derive consistent estimates for $\sigma_{1}^{2}$ and $\sigma_{2}^{2}$ from the residuals of the wage equations and estimated parameters (see Maddala, 1983, pp. 225-26). In our empirical application, we estimated the reduced form probit model and each of the two Heckman selection equations in one step using a maximum likelihood estimator (Greene, 1997). The ML function uses the estimated parameters from the reduced form probit model as starting values for the estimation of the Heckman corrected wage equations.

In the final step, we again use the probit model to estimate the structural equation and to obtain a consistent estimate of $\delta$, the coefficient of the wage differential. Substituting $\ln \widehat{w}_{1 i}=X_{1 i} \widehat{\beta}_{1}$ and $\ln \widehat{w}_{2 i}=X_{2 i} \widehat{\beta}_{2}$ for $\ln w_{1 i}$ and $\ln$ $w_{2 i}$, respectively, allows us to estimate the structural probit equation. As Lee (1979) has demonstrated, the resulting estimates of $\gamma$ and $\delta$ are consistent.

\section{Data}

We perform our empirical analysis of the self-selection of East-West migrants in Germany using individual data from the "IAB-Regionalstichprobe". 2 This data set contains a one per cent sample of all the returns of the social security files of Germany, collected by the Federal Employment Services (Bundesanstalt für Arbeit). The East German sample starts at the beginning of 1992 and the last spells are reported for 1997.

The sample covers employed persons, unemployed persons and individuals who are currently taking a break from employment. Self-employed persons

\footnotetext{
${ }^{2}$ Employee sample, regional file. The IAB-Regionalstichprobe is provided by the German Institute for Employment Research (IAB) at the Federal Employment Services (Bundesanstalt für Arbeit). See Haas (2001) for a brief introduction.
} 
and those who are enrolled in educational programs are not included. Moreover, the sample is censored from above, i.e. individuals whose earnings exceed the rather high ceiling for contributions to the public pension scheme and unemployment insurance in Germany are not reported. ${ }^{3}$ In $1995,86.2 \%$ of the economically active population was captured by the social security files in East Germany (Bender, Haas, and Klose, 2000, p. 3).

The observations of each individual are organised as event data. Every change in the employment situation is collected with the date of its event, but also every year a control return is registered. For each individual, work history, personal characteristics, firm characteristics and regional details are collected. We choose only individuals who are employed full-time on 31 March. The employment state on 31 March of every year is used to transform the event-oriented data into a panel of yearly observations.

It is not trivial to identify East Germans in the data set. For the purpose of our analysis, we define East Germans as follows: (i) they have their first spell in 1992 or later, since East Germans were not included in the IAB sample before; (ii) they are registered in an East German pension scheme ${ }^{4}$ if they are employed, and (iii) they work at a company in East Germany if they are employed. These definitions imply that we do not include those East Germans in our analysis who have migrated to West Germany before 1992.

On the basis of these definitions, we distinguish two groups of individuals: stayers are all individuals that have been registered as employees or unemployed in East Germany for the whole time span from 1992 to 1997 and all individuals who are registered in East Germany, but will later move to West Germany during the observed time period; movers are individuals who are in a spell in the West for the first time, i.e. those who moved during the previous year. Since our regressions are based on a cross-sectional analysis, we do not consider the spells of East Germans who have been residing in West Germany for more than two years. By definition, our sample contains

\footnotetext{
${ }^{3}$ The ceiling was 5,300 DM in 1992 and 7,100 DM in 1997, while the mean incomes in our sample amount to 2,695 and 3,097 for the two years.

${ }^{4}$ Landesversicherungsanstalt (LVA) Ost, Bundesversicherungsanstalt für Angestellte (BfA) Ost, or Knappschaft.
} 
Table 1: Number of observations

\begin{tabular}{cccc}
\hline year & movers & stayers & perc. of movers \\
1994 & 428 & 33038 & 1.30 \\
1995 & 380 & 33677 & 1.13 \\
1996 & 389 & 32418 & 1.20 \\
1997 & 364 & 30878 & 1.18
\end{tabular}

observations for stayers over the whole period from 1992 to 1997, for movers only from 1993 to 1997.

Table 1 shows that the number of individuals in our sample is slightly declining. Some of the individuals may vanish from the sample due to death, international migration, leaving the labour force or becoming unemployed. Moreover, those who reside in West Germany for at least the second year vanish from the sample. Numerically, the highest number of movers is achieved in 1994. In relative numbers, the share of movers diminishes only slightly from $1.3 \%$ in 1994 to $1.2 \%$ in 1997.

\section{Characteristics of East-West migrants}

The following graphs provide some initial insights into the socio-economic characteristics of East-West migrants. Summary statistics for all the variables used in our regressions for the individual years can be found in Table 11.

Figure 2 displays the development of the mean log of wages per day in DM, divided into three groups: stayers and movers as defined above, and a third category, called prospective movers. The last category contains all individuals who are still in East Germany, but will move during the observation period. We include this third group here because the difference between prospective movers and stayers is striking: wages of prospective movers start well below those of stayers, although they receive much the same wage increase as stayers. Note that the lower wage level may reflect the difference in the age of stayers and migrants (see below). However, movers already working in West Germany receive wages above those of stayers in East Germany. 


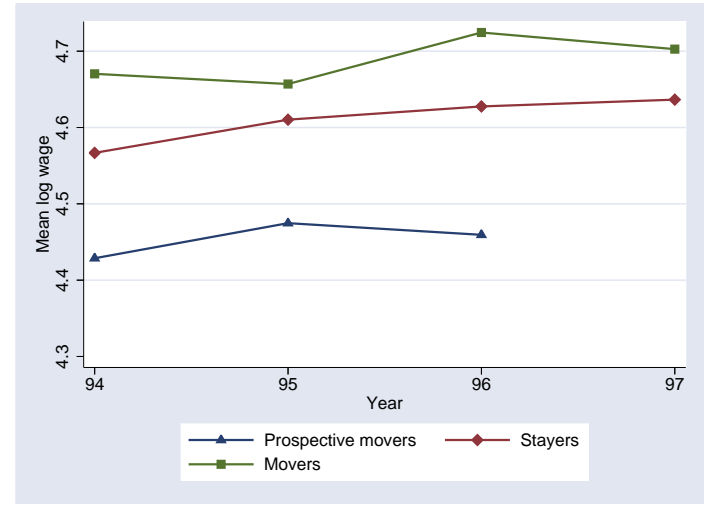

Figure 2: Mean wage

The descriptive statistics of the education variables seem to indicate that East-West migrants are slightly less skilled than the average person in East Germany. We distinguish three groups by their highest education degree: those who possess no vocational education degree, those who possess a vocational education degree, and those who possess a degree from a university or a university of applied sciences. ${ }^{5}$ Figure 3 displays the share of individuals without vocational education degree in the groups of movers and stayers. The share of unskilled is, at around seven per cent, relatively low in the group of stayers, and shows a very strong decline in the group of movers (from around 15 to below 10 per cent).

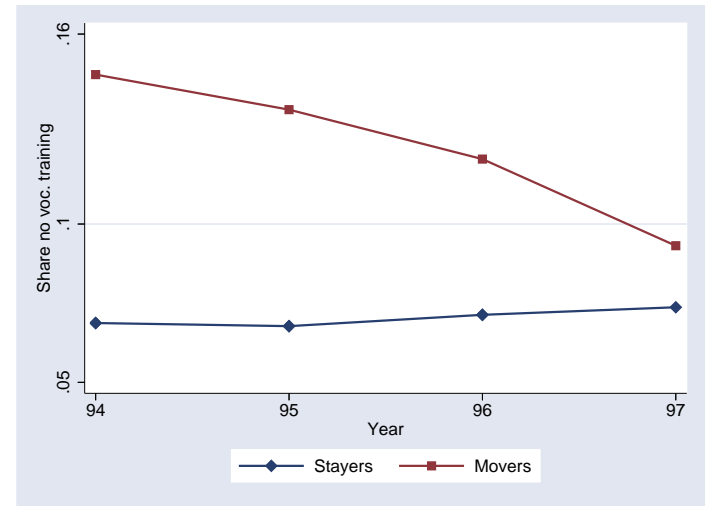

Figure 3: Mean of no vocational training degree

\footnotetext{
${ }^{5} \mathrm{~A}$ fourth group, unknown or missing education, is used in the regressions, but we do not display it here.
} 
Figure 4 shows the individuals with completed vocational training, which is the most common education group in East Germany. The share of individuals with completed vocational training is persistently high at around 74 per cent among the group of stayers, while the share in the group of movers is rising from 60 to 70 per cent, with a spike in 1996.

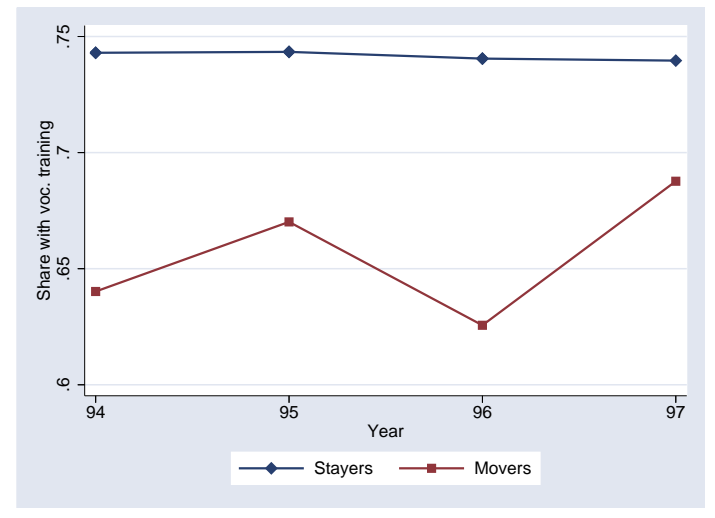

Figure 4: Mean of vocational training degree

Finally, we observe that the share of individuals with an academic education degree is lower in the group of movers than in the group of stayers. Note that, at around 11 per cent, the share of individuals with an academic degree is relatively low in the East German population. While the share of individuals with an academic degree is stable among the group of stayers, we observe that it is increasing from 1995 onward (Figure 5). It is moreover worth noting that our sample covers only individuals who have already participated in the East German labour market, i.e. students and those with an academic degree who take up their first job in West Germany are not considered here. Moreover, individuals with a wage above the ceiling of the social security records are not covered. These exclusions can heavily bias the results with regard to high-skilled jobs.

To summarise, we observe that employed migrants are less skilled than the sample average.

The difference in lagged unemployment rates of movers and stayers is relatively stable with a difference of 10 to 15 percentage points, i.e. unemployment seems to influence the migration decision strongly. Note that the 


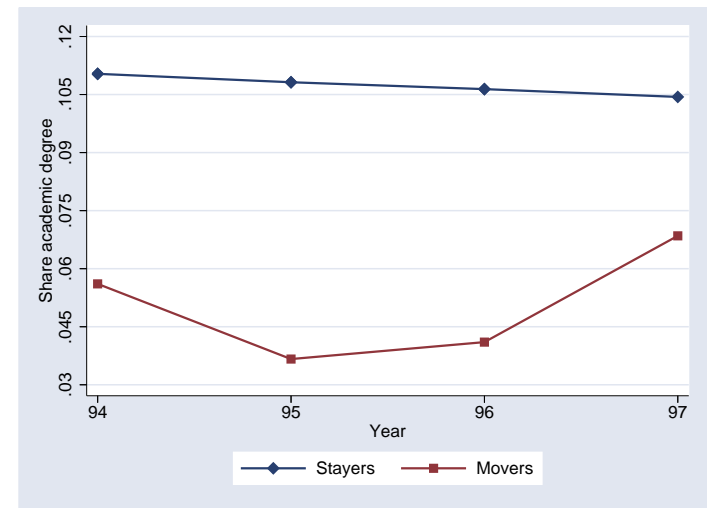

Figure 5: Mean of academic degree

lagged unemployment rate is underreported in our sample, since we excluded those who are unemployed in the present year. Thus, long-term unemployed are not covered by our sample.

Over the whole time span, the mean age of movers is, at round 34 years, persistently five years below the mean age of stayers (39 years). The age increase is less than proportional, because young people are allowed to enter the sample after 1992 if they start working in East Germany. Altogether, the descriptive statistics confirm the hypothesis of the human capital theories of migration that young people have a higher propensity to move.

The other personal characteristics show the following pattern (not displayed here): at the sample mean, the share of males among movers varies between 62 and 71 per cent, while the share of males among the stayers is constant at around 57 per cent. Moreover, there is a persistent difference in the marital status of migrants and stayers: while around 57 per cent of the stayers are married, only around 40 per cent of the movers are. Once again, these results confirm a standard hypothesis from the human capital theory of migration, i.e. that family ties affect the costs of migration.

\section{$6 \quad$ Regression results}

As has been outlined above, the estimation of the switching regression model consists of three steps: firstly, we estimate a reduced form probit model in 
order to obtain a consistent estimate of the individual probability to move. The results from this estimate are used as starting values for a maximumlikelihood estimation of a Heckit selection model of the wage equations for East Germans in West and East Germany. In the final step, consistent estimates of the parameters in the wage equations are used for estimating a structural probit model which includes the estimated potential wage differential for each individual.

The explanatory variables are derived from the human capital theories of migration (Sjaastad, 1961): Beyond the (expected) differential in wages it is assumed that personal characteristics such as age, family ties and education affect the costs and returns to migration, and, hence, the decision to migrate. Moreover, following the traditional approach of Harris and Todaro (1970), we assume that employment opportunities affect expected earnings.

The wage regressions have the traditional Mincer form, i.e. log wages are explained by human capital variables such as education, age brackets, gender, and by occupational status. We do not include marital status in the wage regressions, since this variable is one of those used to identify the model. This is possible because family status turned out not to be significant in determining gross wages and should also not be correlated with the error term of the wage regression.

Furthermore, branch dummies are included. In order to account for regional and branch differences in economic prospects, we also include dummies for the East German Federal States (Bundesländer) and branches. We do not include the West German Bundesländer because we can not construct a counterfactual for stayers, had they moved. The counterfactual Bundesland of movers, had they stayed, is their Bundesland of origin.

Thus, in the wage regressions for East Germany, dummies for the home region (Bundesland), dummies for the home industry branch and the lagged unemployment rate are included. In the decision equation, we include the lags of most variables in order to account for the fact that the decision to migrate was made the year before, which implies that expectations have been formed on basis of the explanatory variables of the past year. 


\subsection{Results from the Heckit regressions}

We estimate four cross-sections for the years 1994 - 1997. The results of the Heckman selection ('Heckit') estimates are reported in Tables 3 to 6 . The coefficients of $\lambda$ as reported in the tables are the covariances $\sigma_{1 \epsilon^{*}}$ and $\sigma_{2 \epsilon^{*}}$, as defined in the wage regressions for stayers and movers (Equations 6 and 7). Note that $\sigma_{1 \epsilon^{*}}=\rho_{1 \epsilon^{*}} \sigma_{1}$ and that $\sigma_{2 \epsilon^{*}}=\rho_{2 \epsilon^{*}} \sigma_{2}$, where $\rho_{1 \epsilon^{*}}$ and $\rho_{2 \epsilon^{*}}$ are the correlation coefficients between the disturbances of the probit and the wage equations. The values of these coefficients are also reported in Tables 3 to 6 .

The signs of the estimated coefficients for $\rho_{1 \epsilon^{*}}$ and $\rho_{2 \epsilon^{*}}$ determine whether the unobserved abilities of individuals are positively or negatively correlated with the wage levels. We find in all four cross-sections that the sign of the correlation coefficient is negative and significant for stayers, and positive and significant for movers. Thus, this can be interpreted as strong evidence that East-West migrants tend to be positively selected with respect to their unobserved abilities. Although the positive selection bias varies somewhat in the different cross-sections, we do not observe that the positive selection bias disappears over time. Thus, the increasing inequality of earnings in Eastern Germany do not seem to have affected the selection bias in our regressions.

The wage differential is calculated on the consistent estimate of wages which are not biased by a selection effect (see Figure 6). If we take into account the selection effect, the wage differential is much higher (see Figure 8). Note that this wage differential cannot be included in the probit regression directly because of the huge difference among stayers and movers which would produce a perfect prediction on who moves and who stays.

The education variables show the expected signs and have a stable effect on wages in East Germany over time. The wage premium for individuals with completed training over individuals without completed training amounts to 13 to 15 per cent. Individuals with a university degree get a wage premium of 37 to 42 per cent. The wage gap between no education and university education amounts, then, to about 40 DM per day. Unknown education also gets a wage premium over no education, but the premium is decreasing over time (from 13.7 per cent to 8 per cent). In West Germany, unknown 


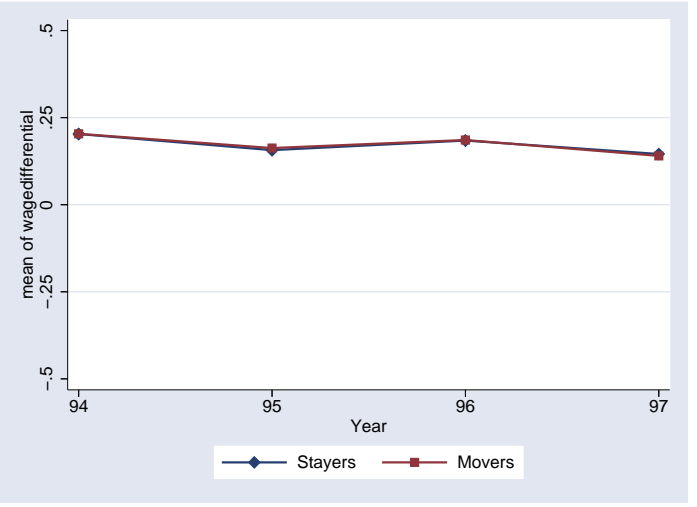

Figure 6: Mean of the wage differential with linear prediction $x_{j} b$

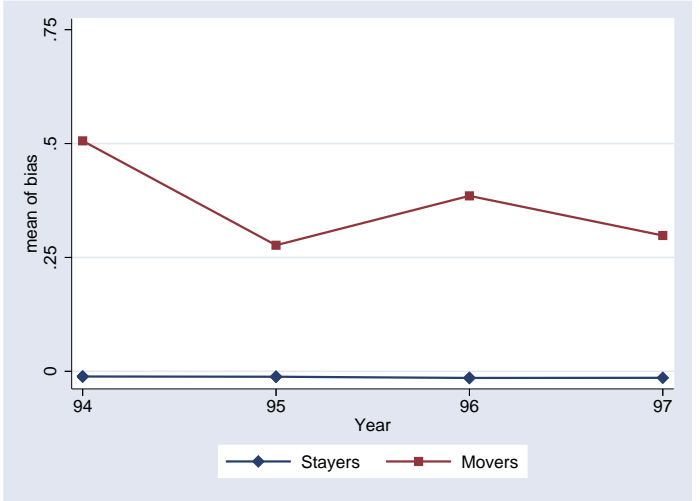

Figure 7: Selection bias for movers in West Germany and stayers in East Germany

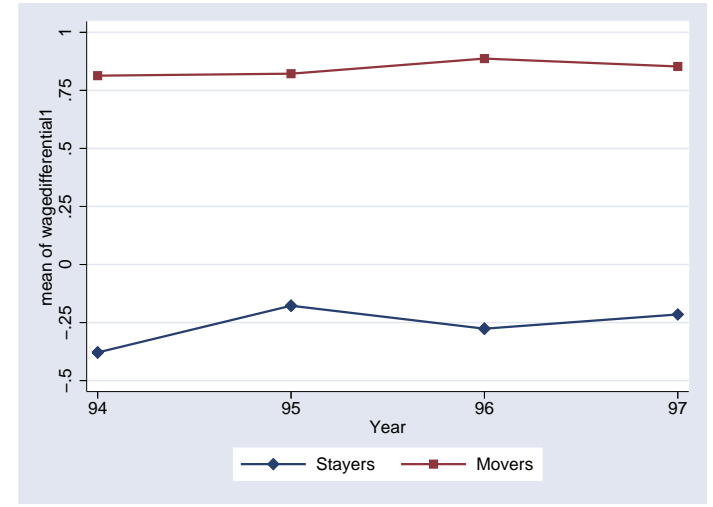

Figure 8: Mean of the wage differential calculated taking into account the sample selection 
education is not rewarded differently than no training. The wage premium for university education is similar to East Germany with a higher volatility of between 33 to 61 per cent. Also the premium of training is similar to East Germany, but the trends of the curves are less smooth, possibly due to the smaller sample size in West Germany.

Workers with completed vocational training receive four to seven per cent higher wages than workers without completed training in East Germany, and white collar workers and foremen receive the highest wages (between 30 and 40 per cent more than workers without vocational training). In West Germany, we observe that only clerks and foremen earn significantly more than the other two groups. Skilled workers get significantly more than unskilled only in the years 1996 and 1997. The insignificant difference between skilled and unskilled workers might be interpreted as evidence for a devaluation of work-specific human capital.

With regard to the age effect on wages, there is again a difference between movers and stayers. Stayers get a shrinking wage increase while moving through the age brackets. This is consistent with the normal findings in wage regressions where the coefficients for age are positive and the coefficients for age squared are negative. From the age bracket 41-50 or latest from the age bracket 51-64 onwards, the wage even decreases. For movers, the picture is less smooth. The standard result of decreasing returns to age is also observable, but there exists a dip in all the observed years with individuals in their thirties getting lower wages than younger movers. Movers also get a less steep wage increase than stayers, which can be explained by the missing tenure of movers.

Men get consistently higher wages than women over time in East and West Germany.

\subsection{Results from the probit estimates}

The results of the reduced form probit regressions are reported in Tables 7 and 8 , and of the structural form probit regressions in Tables 9 and 10. We show only the results for the probability to move. The results for the probability 
to stay can be derived from the results shown by just switching the sign of the coefficients. In the first step (reduced form probit), one can observe the overall effect of the explanatory variables. The effect is composed of the direct effect and the indirect effect which goes through the wage differential. In the second step (the structural probit), only the exogenous variables are included. The variables which are expected to affect wages are excluded because of collinearity between these variables and the wage differential.

The probit regressions explain the probability of an individual to work in West Germany in year $t$ instead of staying in East Germany and working there. The explanatory variables refer to year $t-1$, i.e. they measure the status of a migrant or a stayer in East Germany the year before the observation. We included once again only individuals who are employed in year $t$. All regressions include a large number of individuals, of whom only very few decide to migrate (see Table 1 ).

In the reduced form probit equation we observe some surprising results. Regarding the education variables, we do not find a clear picture like those found in other studies. None of our education variables turn out to be significantly different from zero over time. Only two of the parameters are significant at the ten percent level, but they do not bring any insights regarding the effects of education on the decision to migrate over time. We conclude, therefore, that the education level does not affect the migration decision of workers directly.

Regarding the occupational status, skilled workers tend to move less than unskilled workers with significantly negative parameters from 1994 to 1996. Also clerks and foremen are potentially less likely to move than workers with no vocational training with only one significantly negative parameter in 1996.

The lagged unemployment rate exerts a very important impact on the migration decision. We expected the effect of unemployment to be large because we already observed in the descriptive analysis a huge difference in the lagged unemployment rates of movers and stayers (see Section 5).

Among the personal characteristics, the marital status variable has the expected significant negative effect on migration in almost all cross sections (except 1995). The age brackets show a clear picture during the whole time 
period. The cohorts with an age between 21 and 25 are most likely to move. The oldest age group in the sample, i.e. the cohorts with an age from 51 to 64 years, have the highest propensity to stay in East Germany. All other age groups behave like the reference category aged 17 to 21 .

The other personal and family variables also show the expected results. Males are significantly more likely to move, while married individuals are less likely to move. The children dummy is not significant, perhaps due to the fact that children are underreported in the social security records. ${ }^{6}$ Sector and regional dummies do not show a clear pattern over time. Saxony is the only exception which shows a significant attraction preventing workers from moving to West Germany from 1995 onward. Mecklenburg-Western Pomerania shows a significant positive effect in the structural probit only in 1994.

The wage differential has the expected positive sign in all four crosssections in the structural form probit estimates. The estimated effect of the wage differential has to be interpreted as the minimum effect of the wage differential, because we used the linear predictions not taking into account the selection effect. If we consider the selection effect, the impact of the wage differential would be much higher (see Graph 6).

The second important explanation for the decision to move is lagged unemployment in the structural form probit estimates. This replicates the results from the reduced form probit. It has a positive and highly significant impact on the probability to move. Marital status now has significantly negative effects in all years, while the dummy for children is still not significant. The results for the home regions are also similar to the reduced form. Thus, the economic variables in the structural probit regressions do have the expected signs and are significant.

\footnotetext{
${ }^{6}$ The main reason for underreporting is that only one parent receives welfare benefits from children (like Kindergeld, Kinderfreibetrag), such that the other parent appears as childless in the social security records.
} 
Table 2: Employment and unemployment among stayers and movers

\begin{tabular}{c|ccc|ccc}
\hline \hline & \multicolumn{3}{|c|}{ Stayers } & \multicolumn{3}{c}{ Movers } \\
year & employed & unemployed & percent & employed & unemployed & percent \\
\hline 1994 & 33038 & 4574 & 13.8 & 428 & 51 & 11.9 \\
1995 & 33677 & 4638 & 13.8 & 380 & 44 & 11.6 \\
1996 & 32418 & 6502 & 20.1 & 389 & 82 & 21.1 \\
1997 & 30878 & 6602 & 21.4 & 364 & 88 & 24.2
\end{tabular}

\subsection{Comparision of Probit estimates with and without unemployed}

We have excluded the unemployed from our regressions, which may bias the results if the unemployment rates in the group of movers and stayers and their socio-economic characteristics differ. Table 2 displays the number of employed and unemployed in the groups of movers and stayers. The figures show very similar unemployment rates in both groups. The difference in the characteristics are not displayed here. However, including the unemployed in the probit regressions does not change the results much: the parameters have a similar size and we observe the same pattern of significance. ${ }^{7}$ Thus, we can conclude that the exclusion of the unemployed has not affected our results.

\section{Conclusion}

East Germany inherited from central planning greater equality in the distribution of earnings, but the inequality in earnings has almost approached West German levels in less than ten years since the beginning of transition. The standard Roy model predicts that migrants are favourably selected if the variance of earnings is higher in the host region than in the home region and if the correlation between earnings in both regions is sufficiently strong. Thus, we can derive from the Roy model the hypothesis that migrants from East Germany should have been favourably selected in the beginning, but

\footnotetext{
${ }^{7}$ The results are available from the authors upon request.
} 
that the selection bias should have disappeared over time.

Our findings do not confirm this hypothesis. We analysed the selfselection of East-West migrants in Germany on basis of a switching regression model. The results from our selection regressions provide strong evidence that migrants from East Germany are positively selected with regard to unobserved abilities. Thus, migrants tend to earn more than their staying counterparts if we control for observable human capital characteristics. EastWest migrants do, however, remain positively selected over time although the inequality in the distribution in East Germany has substantially increased. This result clearly contradicts the predictions of the standard Roy model. However, if we relax the assumptions of the standard model and consider moving costs which are negatively correlated with abilities relevant for the labour market performance of individuals, then a persistent positive selection bias is in line with the theoretical expectations resulting from an extended Roy model. Nevertheless, our results should be interpreted with caution, since our sample covers only five years.

In contrast to studies based on other data sources, we do not find that individuals with higher education degrees tend to have a higher propensity to migrate. Conversely, the descriptive statistics in our data set show that skill levels of the migrants are below those of the average person who remains in East Germany. Moreover, we do not find in our reduced form probit regressions any significant impact of education on the propensity to migrate. This holds true for the whole time period covered by our sample. However, these results can be traced back at least partly to the fact that an important group of high-skilled migrants, students and individuals with an academic degree who started their working career in West Germany, is not included in our sample.

Interestingly enough, we find a negative correlation between occupational status and migration probabilities in our reduced form probit regressions. We interpret this as an indication that occupational status is at least partly lost by moving from the East to the West, i.e. that migrants are only partly able to transfer their work experience and firm-specific human capital to the West. 
The wage differential shows a strong positive impact on the propensity to migrate in our structural probit estimates. Moreover, an unemployment event in the period preceding migration turns out to be highly significant. These findings are in contrast to parts of the empirical literature based on individual data sets which do not control for selection bias of migrants. Thus, the results from our switching regression estimates reconcile some of the paradoxical findings in the empirical literature on the impact of wages and other key economic variables on East-West migration in Germany.

Finally, the results from our probit regressions confirm some standard findings from the human capital theories of migration: the propensity to migrate declines with age, married individuals tend to migrate less than unmarried, and males tend to migrate more than females. 


\section{References}

Bender, S., A. HaAs, and C. Klose (2000): "IAB Employment Subsample 1975-1995 - Opportunities for Analysis Provided by the Anonymised Subsample," IZA Discussion Paper, No. 117, IZA Bonn.

BorJas, G. J. (1987): "Self-Selection and the Earnings of Immigrants," The American Economic Review, 77(4), 531-553.

Burda, M. C. (1993): "The Determinants of East-West-Migration: Some First Results," European Economic Review, pp. 452 - 461.

Burda, M. C., W. Härdle, M. Müller, and A. Werwatz (1998): "Semiparametric Analysis of German East-West-Migration Intentions: Facts and Theory," Journal of Applied Econometrics, 13, 525 - 541.

Burda, M. C., And J. Hunt (2001): "From German Reunification to Economic Integration: Productivity and the Labor Market in Eastern Germany," Brooking Papers of Economic Activity, 2:2001, 1-91.

Chiswick, B. R. (2000): "Are Immigrants Favorably Self-Selected? An Economic Analysis," IZA Discussion Paper, 131.

Goldfeld, S., And R. Quandt (1973): "The Estimation of Structural Shifts by Switching Regressions," Annals of Economic and Social Measurement, $2,475-485$.

Greene, W. H. (1997): Econometric Analysis. Prentice Hall International, London, third edition edn.

HAAS, A. (2001): "Die IAB-Regionalstichprobe 1975-1997," ZAInformationen, (48), 128-141.

Harris, J. R., And M. Todaro (1970): "Migration unemployment and development: a two sector analysis," American Economic Review, 60, 126 $-142$. 
Heckman, J. J. (1976): "The Common Structure of Statistical Models of Truncation, Sample Selection and Limited Dependent Variables and a Simple Estimator for Such Model," Annals of Economic and Social Measurement, 15, 475-492.

- (1979): "Sample Selection Bias as a Specification Error," Econometrica, 47, $153-161$.

Heckman, J. J., And B. E. Honore (1990): "The empirical content of the Roy model," Econometrica, 58(5), 1121-1149.

Heckman, J. J., and G. Sedlacek (1985): "Heterogeneity, Aggregation, and Market wage Functions: an empirical model of self-selection in the labor market," Journal of Political Economy, 93(6), 1077-1125.

Hunt, J. (2000): "Why do People Still Live In East Germany?," DIW Discussion Paper, No. 201, DIW Berlin.

Jasso, G., And M. R. Rosenzweig (1990): "Self-selection and the Earnings of Immigrants: Comment," American Economic Review, 80(1), 298304.

LeE, F. (1978): "Unionism and Wage Rates: A Simoultaneous Equation Model with Qualitative and Limited Dependent Variables," International Economic Review, 19, 415-433.

(1979): "Identification and Estimation of Binary Choice Models with Limited (Censored) Dependent Variables," Econometrica, 47, 977 996.

Maddala, G. S. (1983): Limited-dependent and qualitative variables in econometrics. Cambridge University Press, Cambridge.

Maddala, G. S., and F. D. Nelson (1975): "Switching regression models with exogenous and endogenous switching," Proceedings of the American Statistical Association, Business and Economic Statistics Section, pp. 423426. 
Nakosteen, R. A., and M. Zimmer (1984): "Migration and Income: The Question of Self-Selection," Southern Economic Journal, 46(3), 840-851.

Pischke, J. S., M. Staat, and S. Vögele (1994): "Arbeitslosigkeit, Löhne und Weiterbildung: Warum pendeln Ostdeutsche in den Westen," in Arbeitsmarktdynamik und Unternehmensentwicklung in Ostdeutschland, ed. by H. König, and V. Steiner. Nomos.

Roy, A. D. (1951): "Some Thoughts on the Distribution of Earnings," Oxford Economic Papers, 3, 135- 146.

Schwarze, J. (1996): "Beeinflusst das Lohngefälle zwischen Ost- und Westdeutschland das Migrationsverhalten der Ostdeuschen?," Allgemeines Statistisches Archiv, 80, 50 - 68 .

SjaAstad, L. (1961): "The Costs and Returns of Human Migration," Journal of Political Economy, 70, 80 - 93.

Willis, R., And S. Rosen (1979): "Education and Self-Selection," Journal of Political Economy, 87, S7 - S36. 
Table 3: Heckit East German Wages 1994-95 with Selection: Stayer

\begin{tabular}{|c|c|c|c|c|}
\hline$\overline{\text { Variable }}$ & $\overline{\text { Coeff.94 }}$ & (Std.Err.) & Coeff.95 & 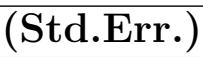 \\
\hline \multicolumn{5}{|c|}{ Dependent variable: $\log ($ wage $)$} \\
\hline With training & $0.149^{* *}$ & $(0.008)$ & $0.130^{* *}$ & $(0.008)$ \\
\hline University or UAS & $0.395^{* *}$ & $(0.010)$ & $0.400^{* *}$ & $(0.010)$ \\
\hline Unknown education & $0.137^{* *}$ & $(0.009)$ & $0.102^{* *}$ & $(0.010)$ \\
\hline Skilled workers & $0.052^{* *}$ & $(0.006)$ & $0.058^{* *}$ & $(0.006)$ \\
\hline Clerks and foremen & $0.354^{* *}$ & $(0.006)$ & $0.371^{* *}$ & $(0.006)$ \\
\hline Age 21-25 & $0.494^{* *}$ & $(0.012)$ & $0.512^{* *}$ & $(0.013)$ \\
\hline Age $26-30$ & $0.597^{* *}$ & $(0.012)$ & $0.618^{* *}$ & $(0.013)$ \\
\hline Age 31-35 & $0.638^{* *}$ & $(0.012)$ & $0.659^{* *}$ & $(0.012)$ \\
\hline Age 36-40 & $0.655^{* *}$ & $(0.012)$ & $0.685^{* *}$ & $(0.012)$ \\
\hline Age $41-45$ & $0.660^{* *}$ & $(0.012)$ & $0.688^{* *}$ & $(0.012)$ \\
\hline Age 46-50 & $0.662^{* *}$ & $(0.012)$ & $0.684^{* *}$ & $(0.013)$ \\
\hline Age 51-64 & $0.665^{* *}$ & $(0.011)$ & $0.679^{* *}$ & $(0.012)$ \\
\hline Sex & $0.226^{* *}$ & $(0.004)$ & $0.240^{* *}$ & $(0.004)$ \\
\hline Brandenburg & $0.043^{* *}$ & $(0.006)$ & $0.055^{* *}$ & $(0.006)$ \\
\hline Meck.-W. Pom & $0.032^{* *}$ & $(0.006)$ & $0.034^{* *}$ & $(0.006)$ \\
\hline Saxony & -0.001 & $(0.005)$ & 0.008 & $(0.005)$ \\
\hline Saxony-Anhalt & $0.017^{* *}$ & $(0.006)$ & $0.019^{* *}$ & $(0.006)$ \\
\hline Agriculture, Cons. Goods & $-0.055^{* *}$ & $(0.005)$ & $-0.042^{* *}$ & $(0.005)$ \\
\hline Goods Production & -0.005 & $(0.005)$ & $0.033^{* *}$ & $(0.005)$ \\
\hline Construction, transport & $-0.093^{* *}$ & $(0.005)$ & $0.079^{* *}$ & $(0.005)$ \\
\hline Intercept & $3.443^{* *}$ & $(0.011)$ & $3.453^{* *}$ & $(0.012)$ \\
\hline$\rho_{1 \epsilon^{*}}$ & $-0.845^{* *}$ & $(0.012)$ & $-0.877^{* *}$ & $(0.010)$ \\
\hline$\sigma_{1}$ & $0.301^{* *}$ & $(0.001)$ & $0.311^{* *}$ & $(0.001)$ \\
\hline$\lambda$ & $-0.255^{* *}$ & $(0.004)$ & $-0.273^{* *}$ & $(0.004)$ \\
\hline $\mathrm{N}$ & \multicolumn{2}{|c|}{33466} & \multicolumn{2}{|c|}{34057} \\
\hline $\mathrm{N}$ cens. & \multicolumn{2}{|c|}{428} & \multicolumn{2}{|c|}{380} \\
\hline Log-likelihood & \multicolumn{2}{|c|}{-8465.171} & \multicolumn{2}{|c|}{-9478.105} \\
\hline$\chi_{(20)}^{2}$ & \multicolumn{2}{|c|}{25372.17} & \multicolumn{2}{|c|}{25473.09} \\
\hline
\end{tabular}

Significance levels : $\quad \dagger: 10 \% \quad *: 5 \% \quad * *: 1 \%$

Reference category: No training, Unskilled worker, Female, Not married, Thuringia,

Building and construction

All variables except $\ln$ (wage) refer to the year before 
Table 4: Heckit East German Wages 1996-97 with Selection: Stayer

\begin{tabular}{|c|c|c|c|c|}
\hline Variable & Coeff.96 & (Std.Err.) & Coeff.97 & (Std.Err.) \\
\hline \multicolumn{5}{|c|}{ "Dependent variable: log(wage) } \\
\hline With training & $0.151^{* *}$ & $(0.009)$ & $0.143^{* *}$ & $(0.009)$ \\
\hline University or UAS & $0.412^{* *}$ & $(0.011)$ & $0.415^{* *}$ & $(0.011)$ \\
\hline Unknown education & $0.104^{* *}$ & $(0.010)$ & $0.082^{* *}$ & $(0.010)$ \\
\hline Skilled workers & $0.054^{* *}$ & $(0.006)$ & $0.069^{* *}$ & $(0.006)$ \\
\hline Clerks and foremen & $0.378^{* *}$ & $(0.006)$ & $0.392^{* *}$ & $(0.007)$ \\
\hline Age 21-25 & $0.519^{* *}$ & $(0.014)$ & $0.516^{* *}$ & $(0.014)$ \\
\hline Age 26-30 & $0.663^{* *}$ & $(0.013)$ & $0.671^{* *}$ & $(0.013)$ \\
\hline Age 31-35 & $0.707^{* *}$ & $(0.013)$ & $0.713^{* *}$ & $(0.013)$ \\
\hline Age 36-40 & $0.733^{* *}$ & $(0.013)$ & $0.739^{* *}$ & $(0.013)$ \\
\hline Age $41-45$ & $0.747^{* *}$ & $(0.013)$ & $0.768^{* *}$ & $(0.013)$ \\
\hline Age 46-50 & $0.722^{* *}$ & $(0.013)$ & $0.743^{* *}$ & $(0.013)$ \\
\hline Age 51-64 & $0.718^{* *}$ & $(0.013)$ & $0.733^{* *}$ & $(0.013)$ \\
\hline Sex & $0.250^{* *}$ & $(0.004)$ & $0.250^{* *}$ & $(0.004)$ \\
\hline Brandenburg & $0.048^{* *}$ & $(0.006)$ & $0.045^{* *}$ & $(0.006)$ \\
\hline Meck.-W. Pom. & $0.036^{* *}$ & $(0.007)$ & $0.030^{* *}$ & $(0.007)$ \\
\hline Saxony & 0.006 & $(0.005)$ & 0.001 & $(0.006)$ \\
\hline Saxony-Anhalt & $0.019^{* *}$ & $(0.006)$ & $0.019^{* *}$ & $(0.006)$ \\
\hline Agriculture, Cons. Goods & $-0.035^{* *}$ & $(0.006)$ & $-0.036^{* *}$ & $(0.006)$ \\
\hline Goods Production & $0.050^{* *}$ & $(0.006)$ & $0.062^{* *}$ & $(0.006)$ \\
\hline Construction, transport & $0.076^{* *}$ & $(0.005)$ & $0.072^{* *}$ & $(0.005)$ \\
\hline Intercept & $3.408^{* *}$ & $(0.012)$ & $3.405^{* *}$ & $(0.012)$ \\
\hline$\rho_{1 \epsilon^{*}}$ & $-0.918^{* *}$ & $(0.007)$ & $-0.919^{* *}$ & $(0.008)$ \\
\hline$\sigma_{1}$ & $0.319^{* *}$ & $(0.001)$ & $0.322^{* *}$ & $(0.001)$ \\
\hline$\lambda$ & $-0.293^{* *}$ & $(0.003)$ & $-0.296^{* *}$ & $(0.003)$ \\
\hline $\mathrm{N}$ & \multicolumn{2}{|c|}{32807} & \multicolumn{2}{|c|}{31242} \\
\hline $\mathrm{N}$ cens. & \multicolumn{2}{|c|}{389} & \multicolumn{2}{|c|}{364} \\
\hline Log-likelihood & \multicolumn{2}{|c|}{-9893.626} & \multicolumn{2}{|c|}{-9739.047} \\
\hline$\chi_{(18)}^{2}$ & \multicolumn{2}{|c|}{26672.68} & \multicolumn{2}{|c|}{26377.80} \\
\hline
\end{tabular}

Significance levels : $\quad \dagger: 10 \% \quad *: 5 \% \quad * *: 1 \%$

Reference category: No training, Unskilled worker, Female, Not married, Thuringia,

Building and Construction

All variables except $\ln$ (wage) refer to the year before 
Table 6: Heckit West German Wages 1996-97 Selection: Mover

\begin{tabular}{|c|c|c|c|c|}
\hline Variable & Coeff.96 & (Std.Err.) & Coeff.97 & (Std.Err.) \\
\hline \multicolumn{5}{|c|}{ Dependent variable: $\log ($ wage $)$} \\
\hline With training & $0.171^{* *}$ & $(0.053)$ & 0.037 & $(0.068)$ \\
\hline University or UAS & $0.352^{* *}$ & $(0.094)$ & $0.430^{* *}$ & $(0.098)$ \\
\hline Unknown education & 0.083 & $(0.056)$ & -0.010 & $(0.072)$ \\
\hline Skilled workers & $0.076^{\dagger}$ & $(0.044)$ & $0.181^{* *}$ & $(0.052)$ \\
\hline Clerks and foremen & $0.337^{* *}$ & $(0.043)$ & $0.466^{* *}$ & $(0.054)$ \\
\hline Age 21-25 & $0.263^{* *}$ & $(0.089)$ & $0.185^{\dagger}$ & $(0.101)$ \\
\hline Age 26-30 & $0.291^{* *}$ & $(0.089)$ & $0.257^{* *}$ & $(0.100)$ \\
\hline Age 31-35 & $0.351^{* *}$ & $(0.089)$ & $0.274^{* *}$ & $(0.100)$ \\
\hline Age $36-40$ & $0.265^{* *}$ & $(0.090)$ & $0.254^{*}$ & $(0.103)$ \\
\hline Age 41-45 & $0.268^{* *}$ & $(0.095)$ & $0.224^{*}$ & $(0.108)$ \\
\hline Age 46-50 & $0.275^{* *}$ & $(0.098)$ & $0.266^{*}$ & $(0.109)$ \\
\hline Age 51-64 & $0.312^{* *}$ & $(0.095)$ & $0.299^{* *}$ & $(0.111)$ \\
\hline Sex & $0.285^{* *}$ & $(0.040)$ & $0.254^{* *}$ & $(0.044)$ \\
\hline Agriculture, Cons. Goods & 0.047 & $(0.059)$ & -0.081 & $(0.067)$ \\
\hline Goods Production & $0.117^{*}$ & $(0.053)$ & $0.161^{* *}$ & $(0.058)$ \\
\hline Construction, transport & $0.121^{* *}$ & $(0.039)$ & $0.175^{* *}$ & $(0.049)$ \\
\hline Intercept & $3.525^{* *}$ & $(0.174)$ & $3.646^{* *}$ & $(0.205)$ \\
\hline$\rho_{1 \epsilon^{*}}$ & $0.477^{* *}$ & $(0.143)$ & $0.359^{\dagger}$ & $(0.191)$ \\
\hline$\sigma_{1}$ & $0.325^{* *}$ & $(0.027)$ & $0.332^{* *}$ & $(0.026)$ \\
\hline$\lambda$ & $0.155^{* *}$ & $(0.058)$ & $0.119^{\dagger}$ & $(0.071)$ \\
\hline $\mathrm{N}$ & \multicolumn{2}{|c|}{33512} & \multicolumn{2}{|c|}{31886} \\
\hline $\mathrm{N}$ cens. & \multicolumn{2}{|c|}{33127} & \multicolumn{2}{|c|}{31526} \\
\hline Log-likelihood & \multicolumn{2}{|c|}{-2034.372} & \multicolumn{2}{|c|}{-1939.869} \\
\hline$\chi_{(16)}^{2}$ & \multicolumn{2}{|c|}{204.42} & \multicolumn{2}{|c|}{268.25} \\
\hline Significance levels : $\quad \dagger: 10 \%$ & $*: 5 \% \quad *$ & $k: 1 \%$ & & \\
\hline \multicolumn{5}{|c|}{$\begin{array}{l}\text { Reference category: No training, Unskilled worker, Female, Not married, Thuringia, } \\
\text { Building and Construction }\end{array}$} \\
\hline All variables except $\ln$ (wage) $r$ & er to the yea & & & \\
\hline
\end{tabular}


Table 7: Probit first step 1994-1995

\begin{tabular}{|c|c|c|c|c|}
\hline Variable & Coeff.94 & (Std.Err.) & Coeff.95 & (Std.Err.) \\
\hline With training & -0.002 & $(0.080)$ & $-0.128^{\dagger}$ & $(0.084)$ \\
\hline University or UAS & -0.068 & $(0.110)$ & -0.156 & $(0.140)$ \\
\hline Unknown education & 0.008 & $(0.095)$ & -0.144 & $(0.095)$ \\
\hline Skilled workers & $-0.159^{*}$ & $(0.063)$ & $-0.152^{*}$ & $(0.068)$ \\
\hline Clerks and foremen & -0.104 & $(0.067)$ & -0.085 & $(0.072)$ \\
\hline Unemployed & $0.640^{* *}$ & $(0.078)$ & $0.587^{* *}$ & $(0.064)$ \\
\hline Age $21-25$ & $0.216^{*}$ & $(0.108)$ & $0.355^{* *}$ & $(0.016)$ \\
\hline Age $26-30$ & 0.013 & $(0.114)$ & 0.046 & $(0.016)$ \\
\hline Age $31-35$ & -0.141 & $(0.115)$ & -0.014 & $(0.016)$ \\
\hline Age $36-40$ & $-0.239^{*}$ & $(0.119)$ & -0.071 & $(0.016)$ \\
\hline Age $41-45$ & -0.175 & $(0.118)$ & -0.097 & $(0.016)$ \\
\hline Age $46-50$ & $-0.211^{\dagger}$ & $(0.126)$ & -0.188 & $(0.016)$ \\
\hline Age 51-64 & $-0.408^{* *}$ & $(0.121)$ & $-0.377^{* *}$ & $(0.016)$ \\
\hline Sex & $0.207^{* *}$ & $(0.048)$ & $0.191^{* *}$ & $(0.055)$ \\
\hline Marital status & $-0.129^{* *}$ & $(0.045)$ & -0.057 & $(0.051)$ \\
\hline Children & 0.020 & $(0.094)$ & 0.076 & $(0.051)$ \\
\hline Agric., Cons.Goods & $-0.120^{\dagger}$ & $(0.063)$ & -0.048 & $(0.122)$ \\
\hline Goods Production & -0.008 & $(0.058)$ & 0.022 & $(0.078)$ \\
\hline Construct., Trans. & -0.064 & $(0.055)$ & 0.016 & $(0.094)$ \\
\hline Brandenburg & $0.112^{\dagger}$ & $(0.065)$ & -0.024 & $(0.071)$ \\
\hline Meck.-W. Pom. & 0.101 & $(0.071)$ & 0.005 & $(0.077)$ \\
\hline Saxony & -0.080 & $(0.062)$ & $-0.193^{* *}$ & $(0.065)$ \\
\hline Saxony-Anhalt & 0.057 & $(0.065)$ & -0.093 & $(0.071)$ \\
\hline Intercept & $-2.111^{* *}$ & $(0.106)$ & $-2.137^{* *}$ & $(0.266)$ \\
\hline $\mathrm{N}$ & \multicolumn{2}{|c|}{34207} & \multicolumn{2}{|c|}{35034} \\
\hline Log-likelihood & \multicolumn{2}{|c|}{-2160.126} & \multicolumn{2}{|c|}{-1944.478} \\
\hline$\chi_{(23)}^{2}$ & \multicolumn{2}{|c|}{305.073} & \multicolumn{2}{|c|}{260.177} \\
\hline
\end{tabular}

Significance levels : $\quad \dagger: 10 \% \quad *: 5 \% \quad * *: 1 \%$

Reference category: No training, Unskilled worker, Female, Not married, Thuringia, Building and Construction

All variables except $\ln$ (wage) refer to the year before 
Table 8: Probit first step 1996-1997

\begin{tabular}{|c|c|c|c|c|}
\hline Variable & Coeff.96 & (Std.Err.) & Coeff.97 & (Std.Err.) \\
\hline With training & 0.005 & $(0.086)$ & -0.032 & $(0.088)$ \\
\hline University or UAS & -0.007 & $(0.119)$ & 0.078 & $(0.117)$ \\
\hline Unknown education & $0.176^{\dagger}$ & $(0.098)$ & 0.113 & $(0.100)$ \\
\hline Skilled workers & $-0.134^{*}$ & $(0.063)$ & -0.097 & $(0.068)$ \\
\hline Clerks and foremen & $-0.127^{\dagger}$ & $(0.068)$ & -0.073 & $(0.072)$ \\
\hline Unemployed & $0.476^{* *}$ & $(0.074)$ & $0.455^{* *}$ & $(0.070)$ \\
\hline Age 21-25 & $0.359^{* *}$ & $(0.128)$ & $0.395^{* *}$ & $(0.127)$ \\
\hline Age $26-30$ & $0.246^{\dagger}$ & $(0.135)$ & 0.207 & $(0.137)$ \\
\hline Age 31-35 & 0.169 & $(0.135)$ & -0.002 & $(0.139)$ \\
\hline Age $36-40$ & 0.082 & $(0.138)$ & -0.052 & $(0.141)$ \\
\hline Age 41-45 & -0.084 & $(0.143)$ & -0.168 & $(0.144)$ \\
\hline Age $46-50$ & -0.023 & $(0.146)$ & -0.128 & $(0.146)$ \\
\hline Age 51-64 & -0.157 & $(0.141)$ & $-0.298^{*}$ & $(0.145)$ \\
\hline Sex & $0.193^{* *}$ & $(0.050)$ & $0.137^{* *}$ & $(0.050)$ \\
\hline Marital status & $-0.179^{* *}$ & $(0.047)$ & $-0.091^{\dagger}$ & $(0.050)$ \\
\hline Children & 0.125 & $(0.089)$ & 0.081 & $(0.088)$ \\
\hline Agric., Cons. Goods & $-0.141^{*}$ & $(0.070)$ & $-0.199^{* *}$ & $(0.074)$ \\
\hline Goods Production & $-0.183^{* *}$ & $(0.071)$ & -0.069 & $(0.066)$ \\
\hline Constr., Transp. & 0.056 & $(0.054)$ & -0.082 & $(0.058)$ \\
\hline Brandenburg & $-0.195^{* *}$ & $(0.065)$ & -0.033 & $(0.066)$ \\
\hline Meck.-W. Pom. & $-0.195^{* *}$ & $(0.073)$ & -0.033 & $(0.072)$ \\
\hline Saxony & $-0.261^{* *}$ & $(0.057)$ & $-0.205^{* *}$ & $(0.061)$ \\
\hline Saxony-Anhalt & $-0.130^{*}$ & $(0.062)$ & $-0.139^{*}$ & $(0.068)$ \\
\hline Intercept & $-2.169^{* *}$ & $(0.119)$ & $-2.142^{* *}$ & $(0.118)$ \\
\hline $\mathrm{N}$ & \multicolumn{2}{|c|}{33516} & \multicolumn{2}{|c|}{31890} \\
\hline Log-likelihood & \multicolumn{2}{|c|}{-1982.069} & \multicolumn{2}{|c|}{-1865.945} \\
\hline$\chi_{(23)}^{2}$ & \multicolumn{2}{|c|}{276.253} & \multicolumn{2}{|c|}{248.205} \\
\hline
\end{tabular}

Significance levels : $\quad \dagger: 10 \% \quad *: 5 \% \quad * *: 1 \%$

Reference category: No training, Unskilled worker, Female, Not married,

Thuringia, Building and Construction

All variables except $\ln$ (wage) refer to the year before 
Table 9: Probability to move 1994-1995, structural results

\begin{tabular}{lcccc}
\hline \multicolumn{1}{c}{ Variable } & Coeff.94 & (Std.Err.) & Coeff.95 & (Std.Err.) \\
\hline Unemployed & $0.658^{* *}$ & $(0.074)$ & $0.589^{* *}$ & $(0.068)$ \\
Wage differential & $0.553^{* *}$ & $(0.186)$ & $0.327^{*}$ & $(0.151)$ \\
Marital status & $-0.248^{* *}$ & $(0.044)$ & $-0.242^{* *}$ & $(0.043)$ \\
Children & 0.004 & $(0.044)$ & 0.068 & $(0.083)$ \\
Brandenburg & $0.141^{*}$ & $(0.072)$ & -0.034 & $(0.066)$ \\
Meck.-W. Pom. & $0.119^{\dagger}$ & $(0.078)$ & 0.024 & $(0.070)$ \\
Saxony & -0.081 & $(0.067)$ & $-0.210^{* *}$ & $(0.060)$ \\
Saxony-Anhalt & 0.060 & $(0.072)$ & -0.094 & $(0.065)$ \\
Intercept & $-2.017^{* *}$ & $(0.133)$ & $-2.129^{* *}$ & $(0.052)$ \\
\hline \hline & \multicolumn{5}{c}{34043} \\
N & \multicolumn{2}{c}{33457} & & -1938.589 \\
Log-likelihood & -2163.287 & \multicolumn{2}{c}{168.843} \\
$\chi_{(8)}^{2}$ & \multicolumn{2}{c}{176.718} &
\end{tabular}

Significance levels : $\quad \nmid: 10 \% \quad *: 5 \% \quad * *: 1 \%$

Reference category: Employed, Not married, no children, Thuringia

All variables except the wage differential refer to the year before

Table 10: Probability to move 1996-1997, structural results

\begin{tabular}{|c|c|c|c|c|}
\hline Variable & Coeff.96 & (Std.Err.) & Coeff.97 & (Std.Err.) \\
\hline Unemployed & $0.471^{* *}$ & $(0.072)$ & $0.482^{* *}$ & $(0.067)$ \\
\hline Wage differential & $0.406^{*}$ & $(0.163)$ & 0.144 & $(0.162)$ \\
\hline Marital status & $-0.299^{* *}$ & $(0.043)$ & $-0.281^{* *}$ & $(0.044)$ \\
\hline Children & 0.140 & $(0.086)$ & 0.068 & $(0.085)$ \\
\hline Brandenburg & $-0.154^{*}$ & $(0.065)$ & -0.017 & $(0.066)$ \\
\hline Meck.-W. Pom. & $-0.157^{*}$ & $(0.071)$ & -0.008 & $(0.071)$ \\
\hline Saxony & $-0.259^{* *}$ & $(0.057)$ & $-0.210^{* *}$ & $(0.061)$ \\
\hline Saxony-Anhalt & $-0.133^{*}$ & $(0.061)$ & $-0.126^{\dagger}$ & $(0.067)$ \\
\hline Intercept & $-1.930^{* *}$ & $(0.054)$ & $-2.083^{* *}$ & $(0.055)$ \\
\hline $\mathrm{N}$ & \multicolumn{2}{|c|}{32803} & \multicolumn{2}{|c|}{31238} \\
\hline Log-likelihood & \multicolumn{2}{|c|}{-2012.15} & \multicolumn{2}{|c|}{-1894.15} \\
\hline$\chi_{(8)}^{2}$ & \multicolumn{2}{|c|}{163.838} & \multicolumn{2}{|c|}{141.101} \\
\hline Significance levels : & $\dagger: 10 \%$ & $: 5 \%$ & & \\
\hline
\end{tabular}


Table 11: Summary 94-97

\begin{tabular}{lcccc}
\hline \hline Variable & Mean94 & Mean95 & Mean96 & Mean97 \\
\hline log(wage) & 4.565 & 4.608 & 4.627 & 4.637 \\
& $(0.397)$ & $(0.408)$ & $0.425)$ & $(0.434)$ \\
Age 17-20 & 0.029 & 0.028 & 0.030 & 0.031 \\
Age 21-25 & 0.079 & 0.080 & 0.075 & 0.071 \\
Age 26-30 & 0.123 & 0.113 & 0.105 & 0.102 \\
Age 31-35 & 0.158 & 0.156 & 0.154 & 0.148 \\
Age 36-40 & 0.157 & 0.155 & 0.154 & 0.156 \\
Age 41-45 & 0.154 & 0.159 & 0.157 & 0.155 \\
Age 46-50 & 0.101 & 0.099 & 0.113 & 0.129 \\
Age 51-64 & 0.198 & 0.211 & 0.211 & 0.207 \\
\hline Male & 0.580 & 0.576 & 0.565 & 0.563 \\
Mover Dummy & 0.013 & 0.011 & 0.012 & 0.011 \\
Unemployed & 0.042 & 0.067 & 0.061 & 0.080 \\
Marital status & 0.558 & 0.565 & 0.571 & 0.574 \\
Children & 0.047 & 0.059 & 0.053 & 0.059 \\
\hline Without training & 0.080 & 0.083 & 0.082 & 0.086 \\
With training & 0.743 & 0.733 & 0.733 & 0.729 \\
UAS or University degree & 0.110 & 0.107 & 0.106 & 0.104 \\
Unknown education & 0.076 & 0.077 & 0.079 & 0.081 \\
\hline Trainees and unskilled & 0.152 & 0.163 & 0.164 & 0.168 \\
Skilled workers & 0.382 & 0.375 & 0.369 & 0.365 \\
Clerks and foremen & 0.465 & 0.462 & 0.467 & 0.467 \\
\hline Brandenburg & 0.181 & 0.179 & 0.177 & 0.176 \\
Mecklenburg-Western Pomerania & 0.123 & 0.123 & 0.124 & 0.125 \\
Saxony & 0.337 & 0.338 & 0.339 & 0.344 \\
Saxony-Anhalt & 0.195 & 0.194 & 0.193 & 0.193 \\
Thuringia & 0.164 & 0.166 & 0.167 & 0.163 \\
\hline Agriculture, Consumption Goods & 0.155 & 0.145 & 0.138 & 0.137 \\
Goods Production & 0.161 & 0.149 & 0.146 & 0.146 \\
Construction, Transport & 0.210 & 0.225 & 0.226 & 0.225 \\
Trade, Services & 0.473 & 0.481 & 0.489 & 0.492 \\
\hline Number of observations & 34207 & 35034 & 33516 & 31889 \\
No. of obs. lnwage & 33457 & 34043 & 32803 & 31238 \\
\hline All & 0.9639 & & \\
\hline
\end{tabular}

All variables except $\ln$ (wage) refer to the year before 